\title{
Geochemical records in the subaqueous Yangtze River delta and their responses to human activities in the past 60 years
}

\author{
LIU Ming \& FAN DeJiang* \\ Key Laboratory of Submarine Geosciences and Technology of Ministry of Education, Ocean University of China, Qingdao 266100, China
}

Received July 6, 2010; accepted September 27, 2010

\begin{abstract}
Based on studies of the geochemical elements of core sediments collected from the subaqueous Yangtze River delta front, combined with ${ }^{210} \mathrm{~Pb}$ and ${ }^{137} \mathrm{Cs}$ nuclide dating, element recording profiles were set up and anthropogenic impacts on the sedimentary records were considered. The results suggest that (1) The core formed since 1945, of homogeneous clay and silt sediments. (2) The content of most elements underwent little change, but the content of $\mathrm{S}$ and $\mathrm{Nb}$ increased gradually. In particular concentrations of these elements and heavy metals increased rapidly and were maintained at high levels in the surface and sub-surface layers (i.e. since the 1990s). The elements $\mathrm{S}$, As and $\mathrm{Nb}$ and principal factor 4 (F4), which were sensitive to anthropogenic impacts, could be used as indicators of human activities. (3) The value of each indicator has increased gradually since 1945, with a sharp increase over the last 20 years. When divided according to changing values of the indicators at $185 \mathrm{~cm}(1955), 97 \mathrm{~cm}(1978), 47$ $\mathrm{cm}$ (1992), and $7 \mathrm{~cm}$ (2003), five periods of the geochemical elements records were obtained. These corresponded to the ages of from the Chinese Civil War to the early stages of planned economy, the implementation of planned economy, the reform and opening-up period, the market economy establishment phase and the environment control and protection stage after 2003, respectively.
\end{abstract}

subaqueous Yangtze River delta, geochemical records, human activity, geochemical proxy, response

Citation: Liu M, Fan D J. Geochemical records in the subaqueous Yangtze River delta and their responses to human activities in the past 60 years. Chinese Sci Bull, 2011, 56: 552-561, doi: 10.1007/s11434-010-4256-3

River deltas, coupling complex physical, chemical, biological and geological processes are major areas of energy and material exchange between land and ocean. They are thus the ideal place to study land-ocean interaction, and have been one of the frontiers of marine geology [1,2]. On the other hand, large-scale discharge of anthropogenic pollutants has meant that large river basins and deltas have been the regions most frequently and extensively affected by human activities, causing environmental degradation and even changes in the substrate environment [3-9]. Because of the high sedimentation rate, both natural and human processes will leave a high resolution record in a delta. That means that deposition processes in deltas as well as anthropogenic impacts can be studied in the sedimentary records

*Corresponding author (email: djfan@ ouc.edu.cn) of deltas.

The Yangtze River, with a drainage area of $1.80 \times 10^{6} \mathrm{~km}^{2}$, is the third largest river in the world; the average annual sediment and water discharges are $4.86 \times 10^{8} \mathrm{~m}^{3} \mathrm{t}$ and $9.28 \times 10^{11} \mathrm{~m}^{3}$, respectively, and form a large-scale modern delta system in the estuary $[10,11]$. The Yangtze River delta economic zone is one of the most developed regions in China. Since anthropogenic pollutant emission increases year by year, the delta and its coastal ecological system have suffered serious environmental deterioration. There have been several studies of the geochemical characteristics and the distribution of heavy metals, nutrients and organic pollutants in sediments from the Yangtze River estuary and its adjacent areas, which indicate a significant human impact in this area [5,9]. In recent years, although the sediment discharge has decreased, N, P and other nutrient discharges of the Yangtze 
River have increased yearly, leading to the frequent occurrence of red tide in the estuary [3,6-8]. It has been reported that the concentrations of organic pollutants and $\mathrm{Pb}$ in cores of the Yangtze River estuary have had a positive response to economic development [4,12]. However, studies of high-resolution sedimentary records coupled with human activities in the Yangtze River delta are scarce.

Based on studies of the geochemical elements and grain size of core sediments collected from the subaqueous Yangtze River delta front, in combination with ${ }^{210} \mathrm{~Pb}$ and ${ }^{137} \mathrm{Cs}$ nuclide dating, the particle size and elemental record profiles since 1945 were established, and the human activities impacts on the sedimentary record were considered. This can provide a reference to understanding sedimentation in large river deltas and evaluation of the anthropogenic impacts on estuaries and deltas.

\section{Materials and methods}

\subsection{Sampling}

The sampling site (station $18: 122^{\circ} 37.132^{\prime} \mathrm{E}, 31^{\circ} 00.990^{\prime} \mathrm{N}$ ) is shown in Figure 1. The sediment core was collected in June 2006 using a gravity corer (226 cm long) deployed from the R/V Dong Fang Hong 2 of the Ocean University of China (OUC). The sampling site was located in the Yangtze subaqueous delta front in $20.4 \mathrm{~m}$ water depth [13].

The core was cut for analysis after transportation to the laboratory. Samples for the grain size test were cut at 0.25 $\mathrm{cm}$ interval, giving 906 samples; for dating analysis, 45

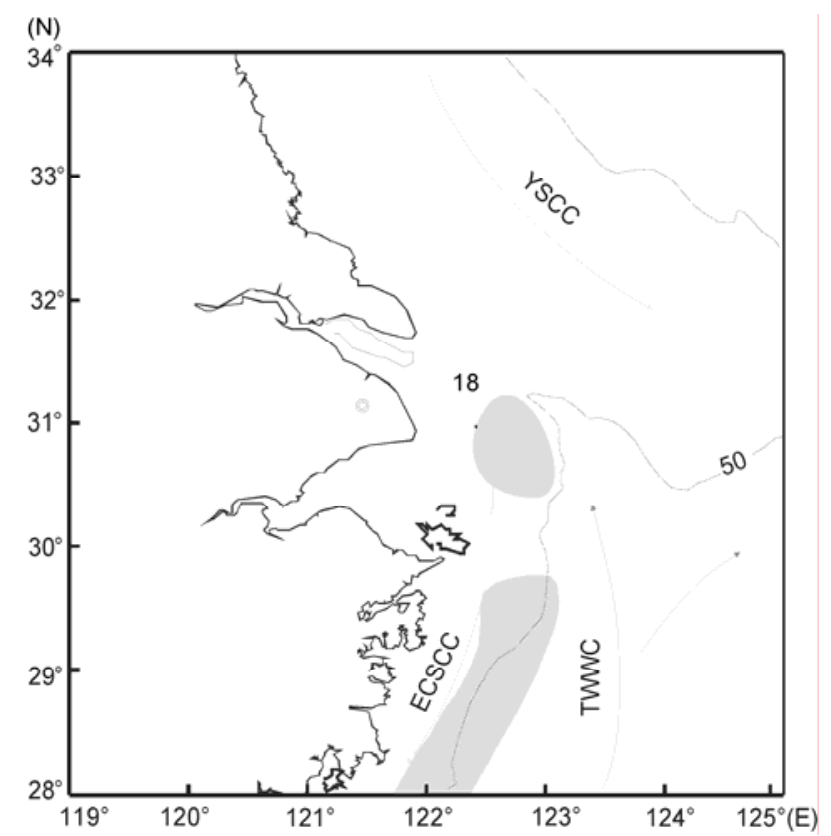

Figure 1 Sample station, water depth and general circulation in the study area compiled after [14,15]. TWWC: Taiwan Warm Current; YSCC: Yellow Sea Coastal Current; ECSCC: East China Sea Coastal Current; shadows indicate muddy sediments. samples of $5 \mathrm{~cm}$ interval were sliced and 76 samples of 3 $\mathrm{cm}$ interval were obtained for geochemical testing.

\subsection{Sample analyses}

(1) Grain size analysis. Grain size was determined by a laser particle size analyzer (Mastersizer 2000, Malvern Instruments Ltd., UK) in the Key Laboratory of Submarine Geosciences and Technology of Ministry of Education, OUC. The grain size interval is $1 / 4 \Phi$, and repeat test relative errors were $<2 \%$. The parameters of grain size were calculated by Folk and Ward's formula [16].

(2) ${ }^{210} \mathrm{~Pb}$ and ${ }^{137} \mathrm{Cs}$ measurements. Measurements of ${ }^{210} \mathrm{~Pb}$ and ${ }^{137} \mathrm{Cs}$ activities in the sediment core were conducted at the Lake Sediment and Environment Laboratory in Nanjing Geography and Lake Institute of the Chinese Academy of Sciences. The instrument used was a $\gamma$ spectrum analysis system, constituting a high purity well germanium detector, an Ortec 919 spectrum controller and an IBM computer (EG \& G Ortec Ltd., USA). The standard samples of ${ }^{137} \mathrm{Cs}$ and ${ }^{226} \mathrm{Ra}$ were provided by the China Institute of Atomic Energy, and a comparative study of the ${ }^{210} \mathrm{~Pb}$ standard samples was done at the University of Liverpool, UK [17].

(3) Geochemical elements analyses. The elemental concentrations were measured using a desktop polarization Energy-dispersive X-ray Fluorescence Spectrometer (EDXRF) (SPECTRO LTD., Germany) in the Key Laboratory of Submarine Geosciences and Technology of the Ministry of Education, OUC. The "TurboQuant-Geo" method was used, and was proved to be reliable in several tests [18]. The measurement quality was controlled using national standards (GSMS-2, stream sediment) and parallel sample measurements. A standard was added after every 10 samples. Relative standard deviations (RSDs) of the standards for most elements were generally $<2 \%$ (the largest was $9.93 \%$ ), indicating the high precision of the instrument.

\section{Results}

\subsection{Sediment components and dating model of the sediment core}

The core sediment was mostly brownish or yellowishbrown, and was composed of sand, silt, and clay, with dominant components of silt and clay. The fractions of sand, silt and clay were $0-12.56 \%, 31.32 \%-88.39 \%, 3.9 \%-$ $60.23 \%$, respectively. Vertically, the silt and clay fractions of sediments were laminated, showing the two components were deposited in sequence. Horizontal stratifications were developed and well-preserved. From the bottom to the top of the core, there were no distinguishing erosion discontinuities (Figure 2).

The activities of excess ${ }^{210} \mathrm{~Pb}$ and ${ }^{137} \mathrm{Cs}$ in the core are 
shown in Figure 2. Through the linear fitting of excess ${ }^{210} \mathrm{~Pb}$ with depth, the average deposition rate was found to be 2.6 $\mathrm{cm} / \mathrm{a}$ with a correlation coefficient of 0.27 , which was inconsistent with other studies of sedimentation rate in this area $[19,20]$. This may be due to frequent natural disasters and the dynamic effects of storms and tides in recent years causing vertical differences in particle size and deposition rate. The absence of physical and chemical calibrations and the uncertainty in the ${ }^{210} \mathrm{~Pb}$ measured data [21] meant that the activities of excess ${ }^{210} \mathrm{~Pb}$ were not applicable in this study.

The ${ }^{137} \mathrm{Cs}$ level has two obvious peaks, corresponding to 1986 (Chernobyl nuclear accident) and 1963 (a large number of nuclear tests in the early 1960s) [22-26] (Figure 2). Previous studies commonly reported the $1963{ }^{137} \mathrm{Cs}$ peak in Yangtze River estuary sediment, while there were few reports of the 1986 peak $[19,20]$. Using the calibration based on the two dated peaks, the average sedimentation rates were $4.35 \mathrm{~cm} / \mathrm{a}$ before 1986 and $2.50 \mathrm{~cm} / \mathrm{a}$ after 1986. The average deposition rate of the whole core was $3.70 \mathrm{~cm} / \mathrm{a}$, which is in good agreement with the results of other studies in this region $[19,20]$. The decrease in average accumulation rate in recent decades can be attributed to the impacts of human activities. According to our calculations, the core has been accumulating since 1945 .

\subsection{Element geochemical records}

(1) Major elements. As shown in Figure 3, the major elements showed little variation along the core. According to the different trends of the element contents, the core could be divided into upper and lower parts at a dividing point at $110 \mathrm{~cm}$ ( 1972). The major elements could be divided into four categories. (1) $\mathrm{Si}$ and $\mathrm{Na}$ showed similar trends in variation, decreasing in the lower part of the core, and fluctuating at $185-170 \mathrm{~cm}(\sim 1955-\sim 1958)$. Both increased sharply after $110 \mathrm{~cm}$ and maintained relatively high levels in the upper part of the core. They fluctuated noticeably at 110-70 cm ( 1972 - 1981), with a high concentration peak at $26 \mathrm{~cm}$ (1996). (2) Concentrations of Al, Mg, Fe, K, $\mathrm{Mn}$ and Ti first increased and then decreased in the lower part of the core. They had obvious fluctuations at 185-170 $\mathrm{cm}(\sim 1955-\sim 1958)$ and 140-110 cm ( 1965 - 1972), with the highest value at $160 \mathrm{~cm}(\sim 1960)$. In the upper layer, fluctuations of these major elements increased, most obviously at $110-70 \mathrm{~cm}(\sim 1972-\sim 1981)$, and became more consistent above $70 \mathrm{~cm}$. There were minor peaks at $26 \mathrm{~cm}$ ( 1996). (3) Cal and P contents were alternately high and low. The peak concentration of $\mathrm{Ca}(4.5 \%)$ appeared at 160 $\mathrm{cm}(\sim 1960)$, with less variation than in other layers.

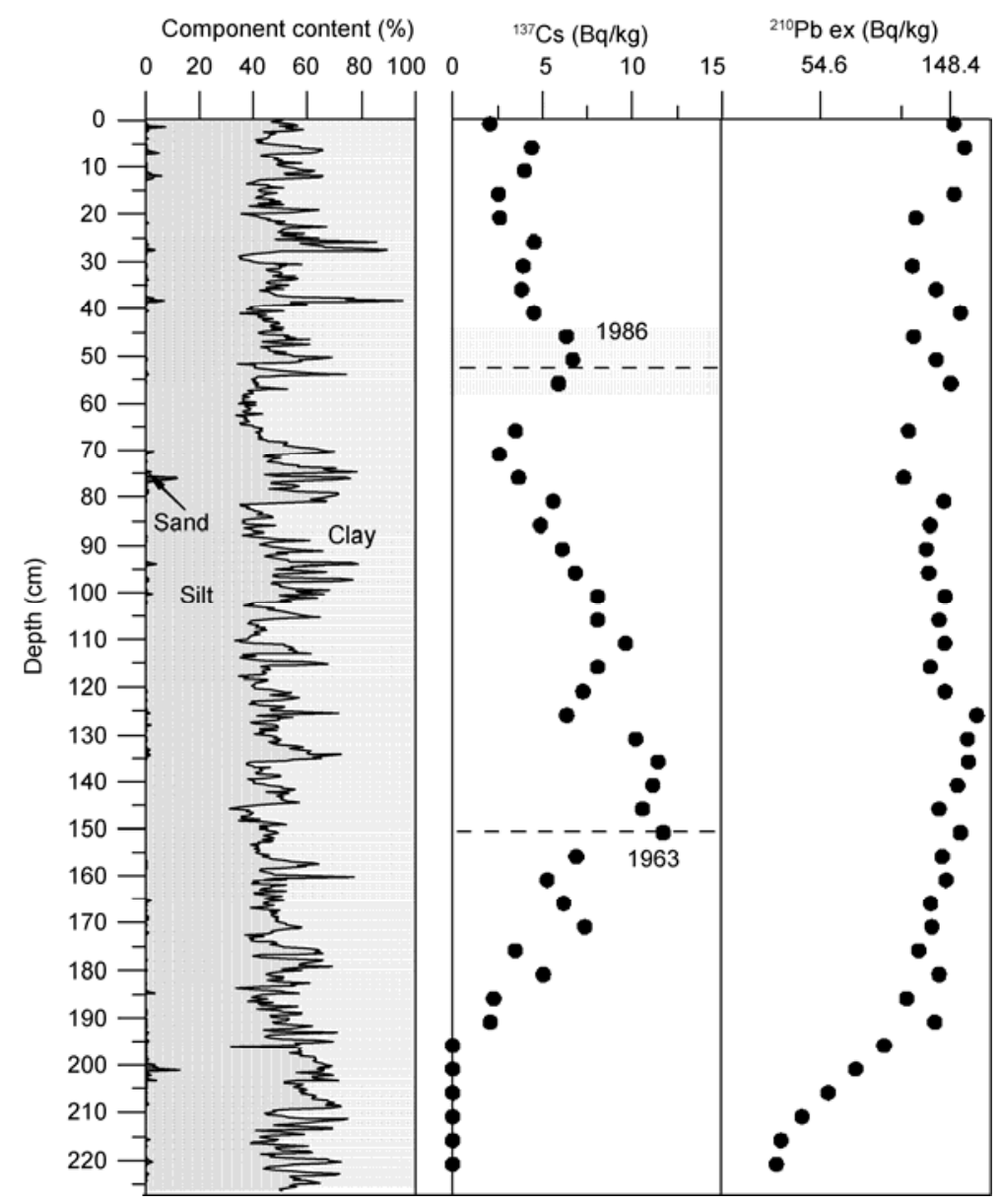

Figure 2 Sediment components and dating model of core 18. 


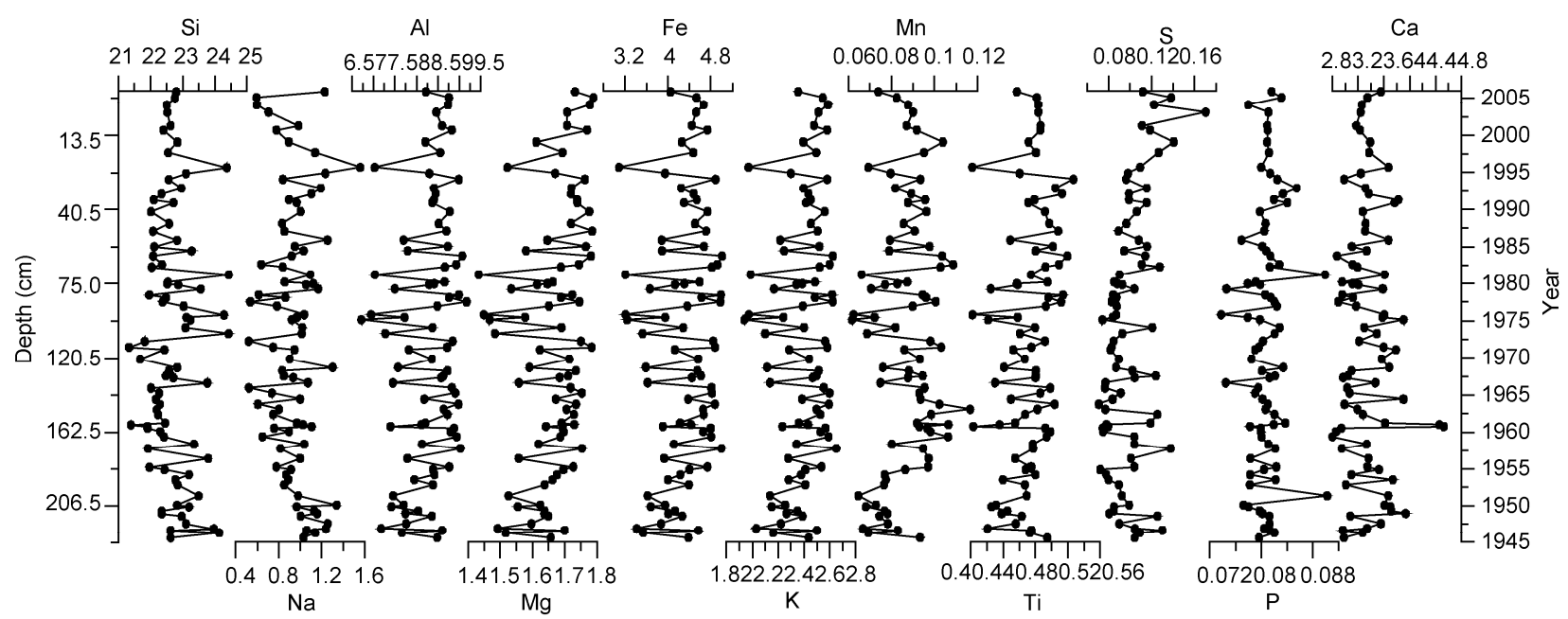

Figure 3 Profiles of major elements in the core (unit: \%).

Phosphorus had comparatively higher values of about $0.09 \%$ at $200 \mathrm{~cm} \mathrm{(} \mathrm{1951)} \mathrm{and} 70 \mathrm{~cm}(\sim 1981)$, with lower values (< $0.075 \%)$ at $130 \mathrm{~cm}, 90 \mathrm{~cm}$ and $80 \mathrm{~cm}$, and a higher abundance above the $30-\mathrm{cm}$ layer. (4) S variation in the core fluctuated less than the other major elements. The $\mathrm{S}$ content was higher below $210 \mathrm{~cm}$, and decreased at 210-180 cm ( 19491958) before increasing gradually, with a sharp increase above $30 \mathrm{~cm}$. It had a higher value (up to $0.14 \%$ ) at 180-165 $\mathrm{cm}(\sim 1956-\sim 1959)$, as well as at $100 \mathrm{~cm}$, and the highest value of $0.17 \%$ was found at $10 \mathrm{~cm}(\sim 2002)$.

(2) Trace elements. The concentrations of trace elements are shown in Figure 4. Like the major elements, the core could be divided into two sections with dividing point at $110 \mathrm{~cm}$, and the trace elements could also be divided into four categories. (1) The vertical variations in all heavy metals and $\mathrm{Rb}, \mathrm{Ga}$ and Th were similar to each other, and consistent with Al. They increased at the bottom and then decreased in the lower part of the core. The highest value was found at $160 \mathrm{~cm}(\sim 1960)$. In the upper sections, fluctuations were larger, with relatively lower values in the $95-\mathrm{cm}$, $70-\mathrm{cm}$, and 22-cm layers. Most of the heavy metals showed a significant rise above $30 \mathrm{~cm}$ (since the 1990s). (2) The vertical variation in $\mathrm{Sr}, \mathrm{Ba}$ and $\mathrm{Zr}$ were consistent with that of Si. Strontium decreased at the bottom of the core before subsequently increasing in the lower part, with the minimum value of $130 \times 10^{-6}$ at $\sim 160 \mathrm{~cm}$, and intense fluctuations in the upper core. Barium showed little variance along the core with lower levels in the lower part of the core; $\mathrm{Zr}$ decreased in the lower part of the core, but increased sharply at $110 \mathrm{~cm}$, and the concentration was higher with only slight fluctuations in the upper section. (3) Y showed little variance throughout the core. The highest value of $30 \times 10^{-6}$ occurred at $200 \mathrm{~cm}(\sim 1951)$ and $70 \mathrm{~cm}(\sim 1981)$, while the lowest $\left(22 \times 10^{-6}\right)$ was found at $190 \mathrm{~cm}$. (4) The concentration of $\mathrm{Nb}$ increased gradually throughout the core sediments with a lot of variability. In the lower section, it first de- creased, and then increased to $21.5 \times 10^{-6}$ at $195 \mathrm{~cm}(\sim 1952)$. The lowest value of $15 \times 10^{-6}$ was found at $155 \mathrm{~cm}(\sim 1961)$. In the upper part of the core, the highest levels occurred at 90 $-60 \mathrm{~cm}(\sim 1976-\sim 1983)$. Although a reduced trend appeared at $60 \mathrm{~cm}$, there was a marked increase from $30 \mathrm{~cm}$ to the top (since the 1990s) with a maximum value of $25 \times 10^{-6}$.

\section{Discussion}

The objective of this work was to explore the responses of sedimentary records to human activities by studying the geochemical elements in this area. Therefore, it was essential to distinguish the indicators that reflect the impacts of human activities. Generally speaking, heavy metals in estuarine sediments were able not only to provide valuable information for geochemical and environmental studies, but also reflect the general pollution status in the target area [5]. Therefore they were regarded as important indicators for human activities. The heavy metals were mainly adsorbed by a variety of clay minerals and oxides, and were thus significantly constrained by the grain size. After normalization with $\mathrm{Al}$, the effect of sediment grain size on heavy metal concentrations could almost be removed and could thus be used as a reference in this work.

Correlations and factor analyses between these elements were conducted to further identify grouped elements to reflect the impacts of human activities.

\subsection{Correlation analysis}

After performing a correlation analysis of major and trace elements and sediment grain size, the results indicated that there was no correlation between $\mathrm{P}, \mathrm{S}, \mathrm{Nb}$ and mean grain size, with low correlation coefficients of $-0.07,0.01,-0.04$ respectively. Silicon, $\mathrm{Na}, \mathrm{Ca}, \mathrm{Sr}, \mathrm{Ba}$ and $\mathrm{Zr}$ had positive 

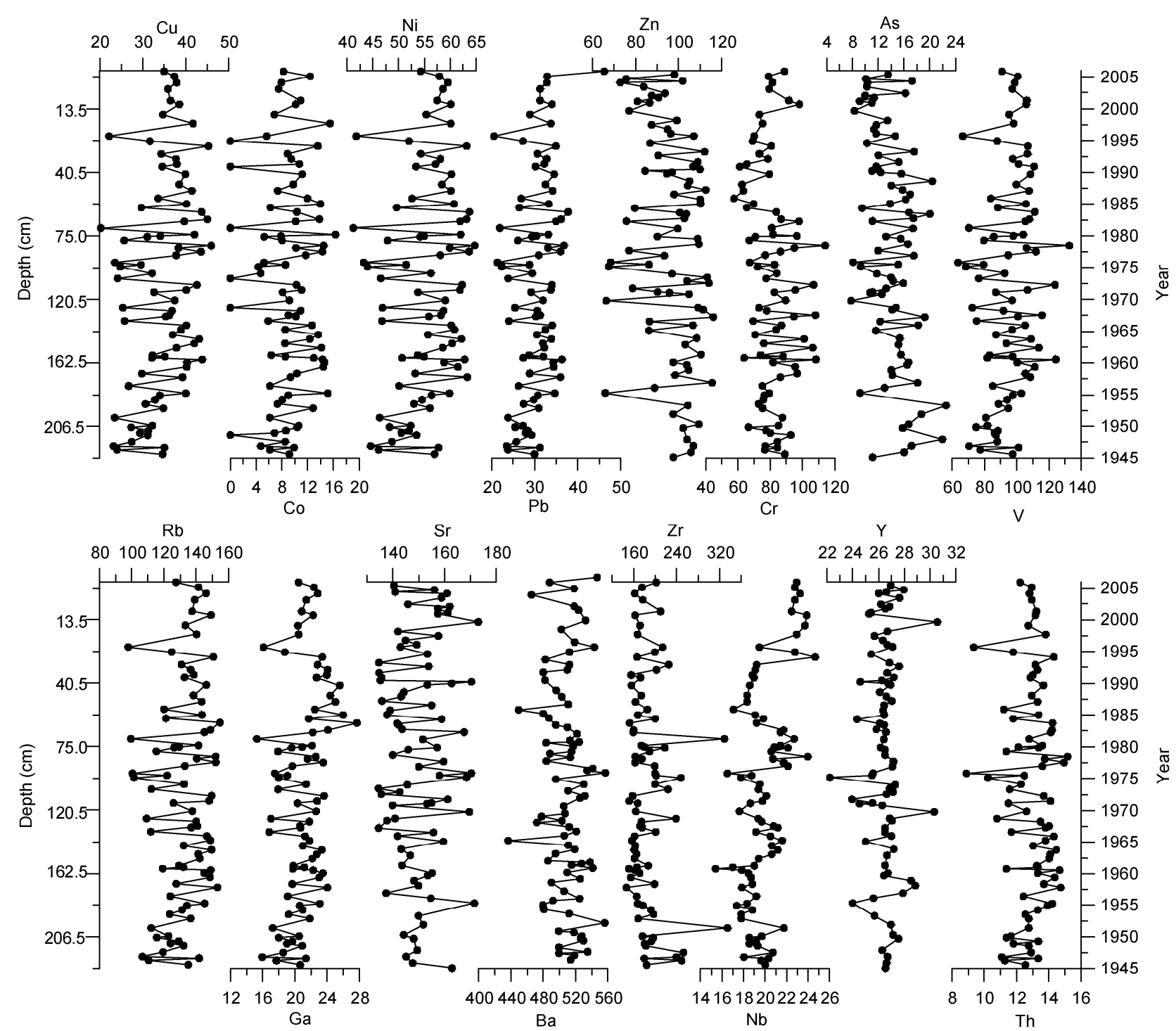

$160 \quad 240 \quad 320$

222426283032
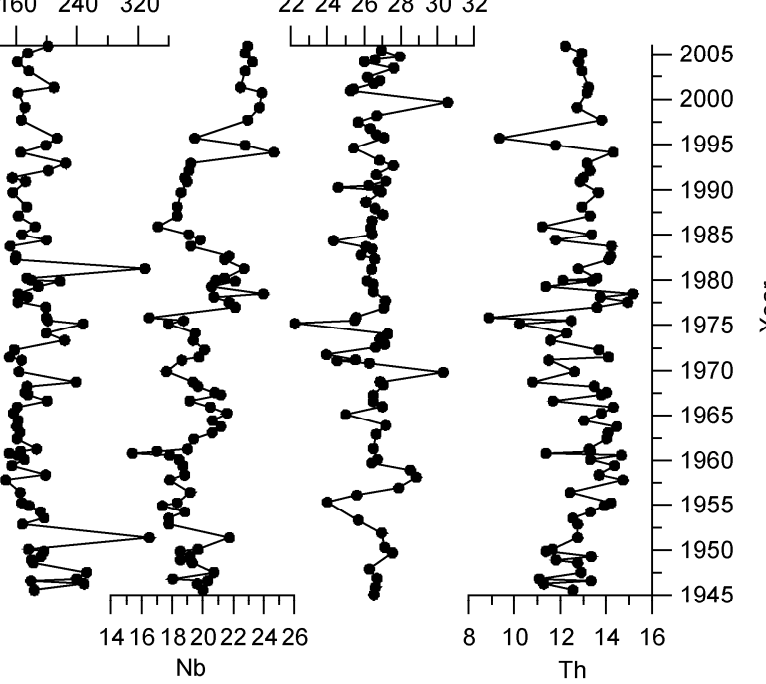

Figure 4 Profiles of trace elements in the core (units: $10^{-6}$ ).

correlations with each other, with the correlation coefficients to mean particle size at 0.5 . The remaining elements showed good positive correlations with each other, but exhibited a negative relationship to particle size, with correlation coefficients of $-0.45--0.61$.

Correlation analysis showed that most elements were constrained by the grain size of the sediment [27], indicating that they are significantly influenced by natural processes. There was no relationship between $\mathrm{P}, \mathrm{S}, \mathrm{Nb}$ and the grain size, as these elements are often associated with agricultural production, combustion processes [28,29] and chemical industries, which are significantly subject to human activities.

\subsection{R-orthogonal rotation factor analysis}

Element contents in marine sediments were controlled by many factors, and there are various reasons for the changes in a single element. But for a certain combination of elements, the driven reason is usually unique, and may indicate the source and sedimentary environment. R-factor analysis is an effective method to identify the combination of the elements, and can be more sensitive and efficient at classifying the elements, thus facilitating discussion of the variation as a whole.

Before the analysis, all the data were normalized at $0-1$, to reduce analytical error and differences in numerical size and/or units between the major and trace elements. After performing factor analysis, as shown in Table 1, the first four common factors, accounting for $81.732 \%$ of total data variance, were identified, representing the main information of the core sediments.

Factor F1, accounting for $60.358 \%$ of the total variance, was the dominant factor affecting changes in element contents. The loadings for Si, Al, Fe, Mg, Mn, Na, K, Ti, V, 
Table 1 R-orthogonal rotation factor loadings of the elements in the core

\begin{tabular}{|c|c|c|c|c|c|c|c|c|c|}
\hline \multirow{2}{*}{ Element } & \multicolumn{4}{|c|}{ Factor loading } & \multirow{2}{*}{ Element } & \multicolumn{4}{|c|}{ Factor loading } \\
\hline & $\mathrm{F} 1$ & $\mathrm{~F} 2$ & F3 & F4 & & $\mathrm{F} 1$ & $\mathrm{~F} 2$ & F3 & F4 \\
\hline $\mathrm{Si}$ & -0.921 & 0.242 & 0.012 & 0.084 & As & 0.646 & 0.070 & -0.015 & 0.621 \\
\hline $\mathrm{Fe}$ & 0.959 & 0.235 & 0.059 & 0.088 & $\mathrm{Ga}$ & 0.878 & 0.131 & 0.029 & 0.020 \\
\hline $\mathrm{Mg}$ & 0.926 & 0.019 & 0.072 & 0.173 & $\mathrm{Rb}$ & 0.944 & 0.274 & 0.043 & 0.120 \\
\hline Mn & 0.862 & 0.006 & 0.027 & 0.047 & $\mathrm{Zr}$ & -0.795 & 0.028 & 0.536 & -0.078 \\
\hline $\mathrm{Na}$ & -0.639 & -0.266 & -0.059 & 0.008 & Th & 0.790 & 0.315 & 0.348 & -0.002 \\
\hline $\mathrm{K}$ & 0.937 & 0.260 & 0.067 & 0.168 & $\mathrm{Ca}$ & -0.344 & -0.900 & -0.014 & -0.140 \\
\hline $\mathrm{Ti}$ & 0.649 & 0.545 & 0.436 & 0.069 & $\mathrm{P}$ & 0.010 & -0.053 & 0.939 & 0.171 \\
\hline $\mathrm{V}$ & 0.863 & 0.283 & 0.153 & 0.072 & $\mathrm{Y}$ & 0.143 & 0.126 & 0.940 & -0.005 \\
\hline $\mathrm{Cu}$ & 0.944 & 0.219 & 0.007 & 0.037 & $\mathrm{~S}$ & 0.071 & 0.032 & 0.068 & 0.914 \\
\hline $\mathrm{Ni}$ & 0.945 & 0.271 & 0.023 & 0.093 & $\mathrm{Nb}$ & 0.084 & 0.407 & 0.291 & 0.548 \\
\hline $\mathrm{Zn}$ & 0.950 & 0.255 & 0.066 & 0.131 & $\mathrm{Cr}$ & 0.402 & 0.296 & 0.137 & 0.085 \\
\hline
\end{tabular}

$\mathrm{Cu}, \mathrm{Ni}, \mathrm{Pb}, \mathrm{Zn}, \mathrm{As}, \mathrm{Sr}, \mathrm{Ga}, \mathrm{Rb}$, Th and Zr, had significantly positive or negative correlations with the average grain size. Therefore, F1 mainly reflected the grain size effect.

Factor F2 contributed $9.761 \%$ of the data variance through the loadings of $\mathrm{Ca}$ and $\mathrm{Sr}$. Ca mainly existed in the form of carbonate, with the main origin being biological debris. Sr also mainly existed in carbonate materials of biogenic origin, while the contribution of terrigenous origin was less than $20 \%$ [30]. The geochemical behaviors of $\mathrm{Ca}$ and $\mathrm{Sr}$ were similar to each other. F2 is thus attributed to marine biological processes.

Factor F3, with a variance contribution of $6.304 \%$, was correlated with $\mathrm{Zr}, \mathrm{P}$ and $\mathrm{Y}$. These were always found in heavy minerals and were transported with debris, exhibiting a high concentration in coarser components than in clay, suggesting hydrodynamic control. Zr, P and Y mainly occur in zircon, apatite and xenotime, and various mineral and rare-earth mines have been developed in the upper reaches of the Yangtze River. Thus F3 is mainly associated with the combined effects of the geological background of the source area and hydrodynamic forces.

Factor F4 accounted for $5.309 \%$ of the total variance, through the loadings of $\mathrm{S}, \mathrm{As}$ and $\mathrm{Nb}$. The major sources of $\mathrm{SO}_{2}$ in China are associated with tail gas emissions of sulfuric acid plants, non-ferrous metal smelting, and the coal fires. A major source is coal-fired flue gas, which contributes $85 \%-90 \%$ of $\mathrm{SO}_{2}$ pollution [28,29]. Human activities are a major source of As. Mining and smelting of sulfide ores, the chemical industry, and coal-fired processed produce large amounts of arsenic waste water, gas and residue. As in the atmosphere is mainly from coal combustion and ore smelting, and other sources like agricultural irrigation using sewage, industrial sludge, arsenic fertilizers, and pesticides [31]. Pure metal $\mathrm{Nb}$ is used to dispose of the residual gas in electronic tubes, and has been widely used in metallurgy, the iron and steel industries, and manufacturing of high- temperature metal-ceramics. It is often in the form of niobate. Therefore, factor F4 is believed to reflect the impact of anthropogenic activities.

To further analyze changes in the factors and their responses to deposition processes, their scores were calculated and are shown in Figure 5. The first three factors had some fluctuations in scores, but no significant increase or decrease overall, indicating the stability of natural processes in the last 60 years. However, the increasing trend of factor F4 was very explicit in recent decades, showing the gradual intensification of human activities.

\subsection{Response to human activities of elements records}

Correlation analysis showed that the concentrations of $\mathrm{S}, \mathrm{P}$ and $\mathrm{Nb}$ were less affected by particle size, and may reflect the impacts of human activities. But R-factor analysis showed that element $\mathrm{P}$ was mainly affected by the background of the source area, while factor F4, with S, As and $\mathrm{Nb}$ having the highest loadings, reflected the impact of human activities. Therefore, contents of $\mathrm{S}, \mathrm{Nb}, \mathrm{As}$ (as a ratio with $\mathrm{Al}$ ) and scores of factor F4 mainly reflected human activities, they and the heavy metals could be regarded as proxies to human activities in the study area.

Gross domestic product (GDP) is often recognized as the best indicator of national economic development. China's economic construction has achieved great success in the last 60 years, maintaining a trend of GDP growth, with a particularly rapid increase since the 1980s. However, economic development was not steady and has been accompanied by many upturns and downturns, as can be clearly seen in the trend of GDP growth rate [32].

By comparison the indicators of human activity were closely related to the changes in GDP growth; in particular F4 had a good agreement with the growth rate of GDP (Figure 6). According to their fluctuations, five stages of human activities could be distinguished.

(1) The first stage was below $185 \mathrm{~cm}$ (i.e. before 1955), 


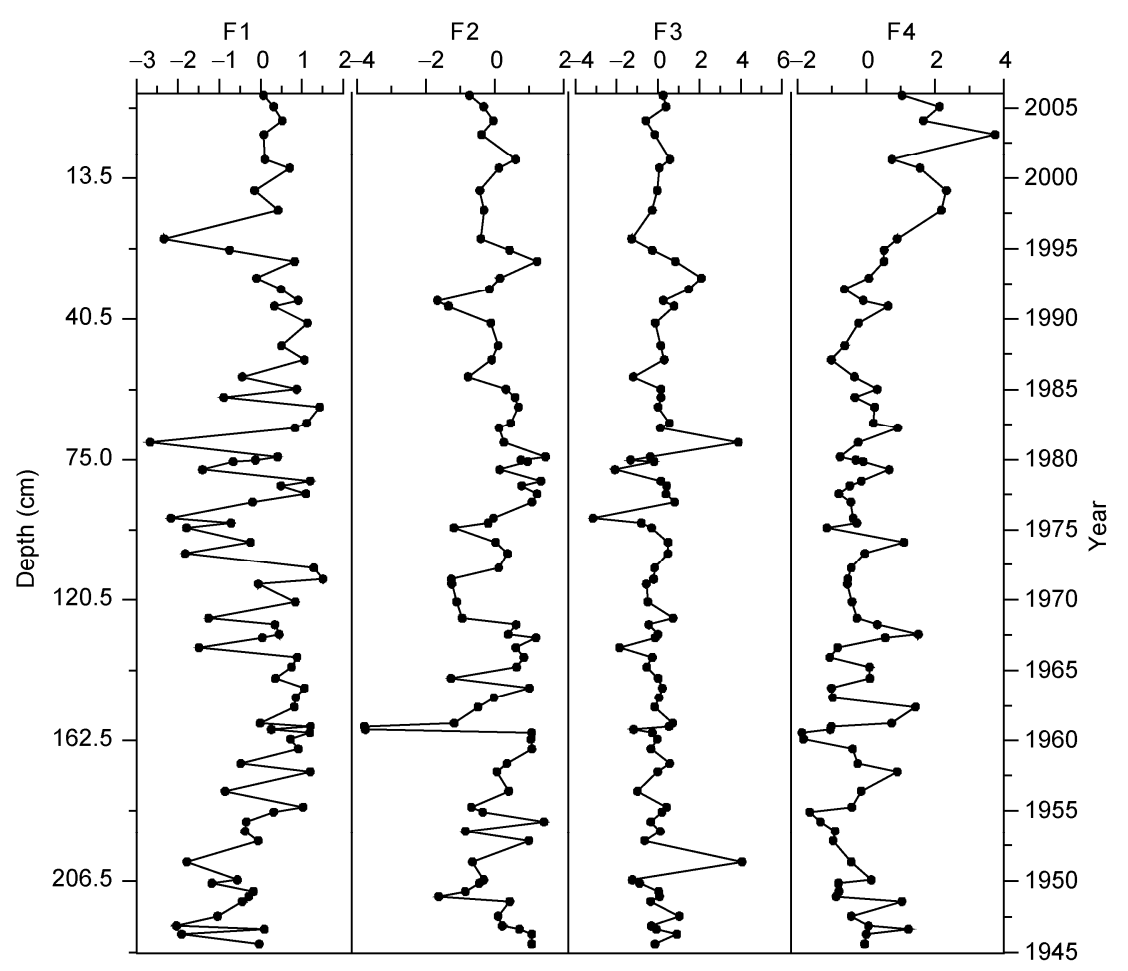

Figure 5 The profiles of the four factors in the core.

showing a trend of gradual reduction. The F4 score value was about 1 in 1946 and 1948, then reduced to -1.6 in 1955. Contents of S and As were consistent with F4. The Nb content peaked in 1951 and then decreased. Heavy metal contents were higher before 1947, and then decreased with some fluctuations.

The years 1945-1955 were the period from the eve of China's War of Liberation (1945-1949) to the founding of the planned economy of New China. During the war, industrial production became paralyzed and eventually dramatic slowdown. Light industrial output decreased by $30 \%$ in 1949 compared with that before China's War of Liberation, while heavy industry decreased by $70 \%$ [32]. The industrial economy did not recover until after the subsequent foundation of the People's Republic of China, so the pollutants discharged by human activities were relatively low at that time. As a result, the F4 score and other indices were higher to start with and decreased from 1948, showing a good correlation with economic development.

(2) The second stage was from 185 to $97 \mathrm{~cm}$ (i.e. 1955-1975). The index values were higher and fluctuated more than those of the previous stage. F4 was much higher in 1957, 1962, 1967 and 1974, with values of 0.9, 1.43, 1.5 and 1.1 , respectively. F4 had a low value of about -1 in 1963, 1965 and 1975, with the minimum value of -1.86 in 1960. Concentrations of As and $\mathrm{S}$ had similar trends to factor $\mathrm{F} 4$, while concentrations of $\mathrm{Nb}$ showed little variation, with low values in 1961 and 1969. The concentrations of heavy metals fluctuated irregularly, with relatively high values in 1957, 1961 and 1968.
The period of 1955-1975 was the implementation period of the planned economy. The national economy underwent significant development, with many setbacks and shortfalls. During the "First Five-Year Plan" period, the economy had recovered to some extent, and the industrial output was 78.39 billion RMB in 1957, an increase of $128.3 \%$ compared with 1953 [32]. But the "Great Leap Forward" movement in 1958-1960 and serious series of natural disasters in the following 3 years, led to serious economic difficulties in the early 1960s. Although the economy had recovered slightly by the adjustment in 1965, the following "Cultural Revolution" resulted in serious economic deterioration [32,33]. During this period, the fluctuations of the proxies, especially F4, were consistent with the stages of economic development.

(3) The third period was between $97-47 \mathrm{~cm}$ (i.e. 1978-1987). The value of each proxy fluctuated less, but increased slowly over the whole period. F4 increased after 1976, reached 0.66 in 1979 and 1.00 in 1982. It then reduced sharply during 1986-1987, and had nearly dropped to -1 by the end of the period. Both $\mathrm{S}$ and As were consistent with F4. The $\mathrm{Nb}$ content increased during 1977-1982, peaking in 1978 and then reducing gradually after 1982, reaching a minimum value in 1987 . In addition, most metal contents also exhibited high levels in 1981, and then decreased.

This stage corresponded to the period of reform and opening up for China. GDP increased year by year, resulting in a distinct increase in pollutant emissions. All the indicators achieved their highest levels in 1986. After the excessive 


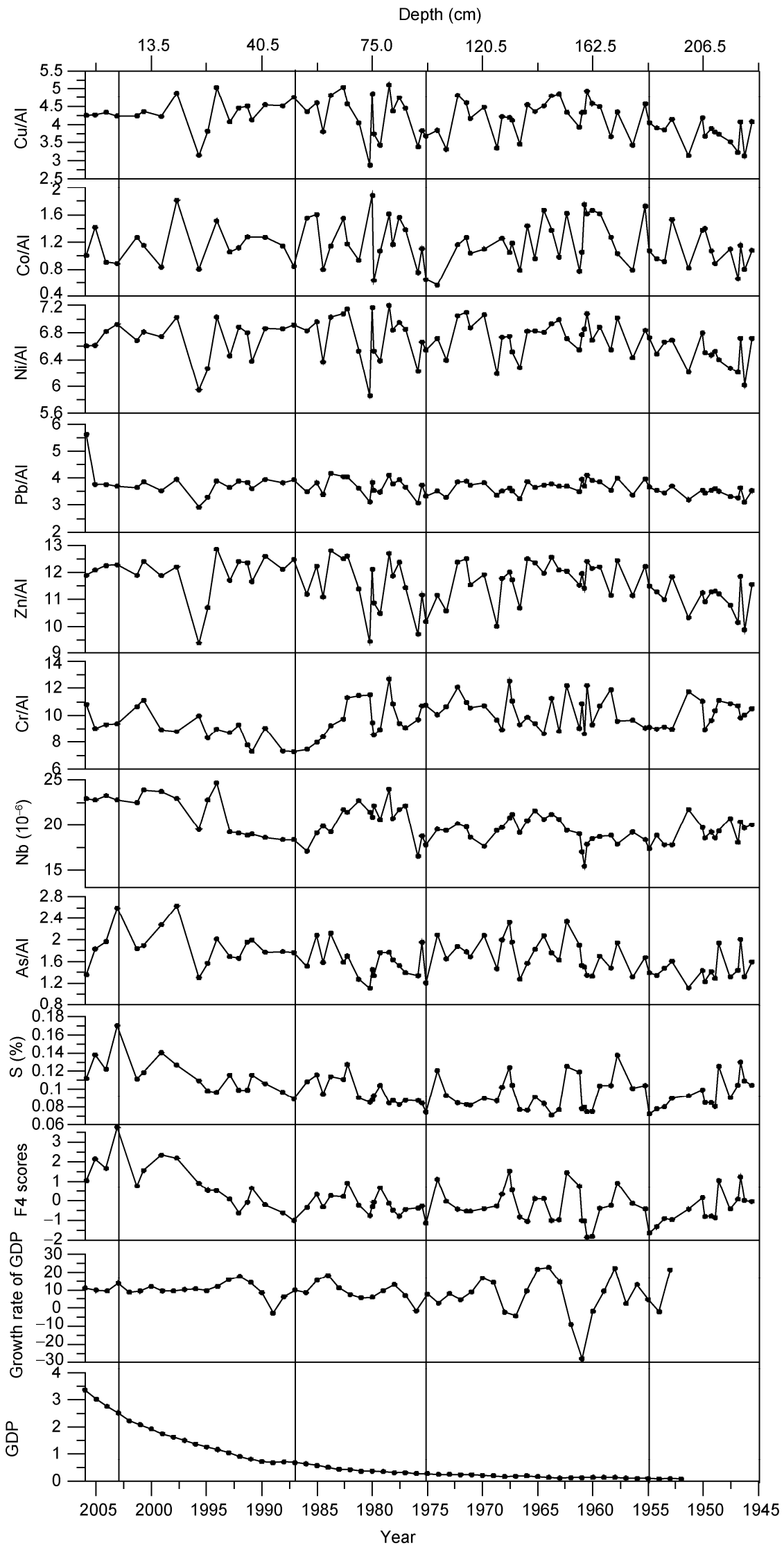

Figure 6 Proxies' records in the sediment core and their response to China's GDP growth (The unit of GDP is trillion yuan, and they were calculated by the price of 1950). 
development during the middle and late 1980s, economic development slowed, causing a continued decrease of the GDP growth rate in 1985-1989 [32,33]. At the same time, the "Soil and Water Conservation" carried out in the upper and middle reaches of the Yangtze River, together with the reduced discharge of pollutants, meant that the indicator values declined during 1987-1991, reaching a minimum in 1991.

(4) The fourth stage was at 47-7 cm (i.e. 1987-2003). Although there were some fluctuations, every proxy rapidly increased over this period. The F4 score increased from -1 to 3.5, while $\mathrm{S}$ and As also increased sharply. Most heavy metals increased rapidly during this period, especially $\mathrm{Nb}$ after 1995.

China experienced further reform and opening up, and established a market economy system during this time. Remarkable economic achievements were made. As the GDP increased rapidly, a large number of organic fuels were combusted and copious industrial waste was discharged, causing rapid environmental deterioration while human life improved enormously. The Yangtze delta area became a sink for heavy metals, with the frequent occurrence of red tides [5-8]. As a result, the proxies also increased rapidly during this period.

(5) The last period corresponded to $7 \mathrm{~cm}$ and above (i.e. 2003-2006). The F4 score dropped from 3.5 to $\sim 1$, and concentrations of $\mathrm{S}$ and As began to decrease, while the concentration of $\mathrm{Nb}$ changed little. The concentrations of $\mathrm{Zn}$, Ni and $\mathrm{Cr}$ also reduced, while the other heavy metals scarcely changed or increased more slowly than before.

In recent years China, along with the rest of the world, has paid much attention to the consequences of environmental degradation. The plan introduced to control emissions of pollutants and to enhance management and protection of the environment has been effective for reducing the emission of pollutants in the environment.

\section{Conclusions}

(1) The correlation and factor analysis of geochemical elements showed that concentrations of the elements S, As and $\mathrm{Nb}$ and the scores of principle factor F4 are mainly attributed to human activities. Their records in the core sample, particularly the F4, were consistent with the GDP growth rate, reflecting close responses to human activities. They could therefore be used as proxies for human activities in estuaries with high deposition rates.

(2) In the last 60 years, the indicators reflected that human activities have gradually increased, especially in the last 20 years. The records could be divided into five periods at the dividing points of $185 \mathrm{~cm}$ (1955), $97 \mathrm{~cm}$ (1978), 47 $\mathrm{cm}$ (1992) and $7 \mathrm{~cm}$ (2003), which correspond to the different socioeconomic development stages in China: from the eve of China's War of Liberation to the early stage of the planned economy, the implementation of the planned economy, the reform and opening-up period, the market economy establishment stage, and the environment control and protection stage, respectively.

This work was supported by the National Natural Science Foundation of China (40976020) and the National Basic Research Program of China (2005CB422304).

1 Hori K, Saito Y, Zhao Q H, et al. Sedimentary facies and Holocene progradation rates of the Changjiang (Yangtze) delta, China. Geomorphology, 2001, 41: 233-248

2 Zhao H Y, Dai S B, Yang S L, et al. Progress in studying on the delta evolution influenced by the human activity (in Chinese). Mar Sci, 2007, 31: 83-87

3 Gao S, Wang Y P. Changes in material fluxes from the Changjiang River and their implications on the adjoining continental shelf ecosystem. Cont Shelf Res, 2008, 28: 1490-1500

4 Hao Y C, Guo Z G, Yang Z S, et al. Tracking historical lead pollution in the coastal area adjacent to the Yangtze River Estuary using lead isotopic compositions. Environ Pollu, 2008, 156: 1325-1331

5 Meng Y, Liu C Y, Cheng J. Geochemical characteristics of heavy metal elements in the surface sediments in Yangtze River estuarine area and evaluations of the bed materials (in Chinese). Mar Geol Quat Geol, 2003, 23: 37-43

6 Shen Z L, Lu J P, Liu X J, et al. Distributions of nutrients in Changjiang River estuary and the impact of Three Gorges Project (in Chinese). Mar Sci, 1992, 33: 107-129

7 Ye X S, Zhang Y, Xiang Y T, et al. Characteristic of nitrate distribution in the Changjiang River estuary and its cause of formation (in Chinese). Mar Sci Bull, 2000, 19: 89-92

8 Ye S F, Ji H H, Cao L, et al. Red tides in the Yangtze River Estuary and adjacent sea areas: Causes and mitigation (in Chinese). Mar Sci, 2004, 28: 26-32

9 Sheng J J, Fan D J, Yang D F, et al. Distribution patterns of heavy metals in surface sediments of the Changjiang estuary and its adjacent areas and environmental quality assessment (in Chinese). Environ Sci, 2008, 29: 2405-2412

10 Milliman J D, Meade R H. World-wide delivery of river sediments to the ocean. J Geol, 1983, 91:1-21

11 Yang, Z S, Wang, H J, Saito Y, et al. Dam impacts on the Changjiang (Yangtze) River sediment discharge to the sea: The past 55 years and after the Three Gorges Dam. Water Resour Res, 2006, 42, W04407. doi: 10.1029/2005WR003970

12 Guo Z G, Lin T, Zhang G. The sedimentary fluxes of polycyclic aromatic hydrocarbons in the Yangtze River estuary coastal sea for the past century. Sci Total Environ, 2007, 386: 33-41

13 Chen Z, Song B, Wang Z, et al. Late Quaternary evolutionof the subaqueous Yangtze delta, China: Sedimentation, stratigraphy, paleontology and deformation. Mar Geol, 2000, 162: 423-441

14 Su J L. Circulation dynamics of the China seas north of $18 \mathrm{~N}$ coastal segment. In: Robinson A R, Brink K H, eds. The Sea, Volume 11, Chapter 16. New York: John Wiley \& Sons Inc, 1998. 483-505

15 Fan D J, Qi H Y, Xu L. Bioturbation in surficial sediments of subaqueous Changjiang (Yangtze) River delta (in Chinese). Oceanol Limnol Sin, 2008, 39: 577-584

16 Folk R L, Ward W C. Brazos river bar: a study of significance of grain size parameters. J Sediment Res, 1957, 27: 3-26

17 Xia W L, Xue B. Accumulation rates based on ${ }^{210} \mathrm{~Pb}$ and ${ }^{137} \mathrm{Cs}$ dating of Xiao Long Bay in JiLin province (in Chinese). Quat Sci, 2004, 24: 124-125

18 Liu M, Xu L, Zhang A B, et al. The use of desktop polarization X-ray fluorescence spectrometry in the marine sediments geochemical analysis (in Chinese). J Ocean Univ Chin, 2009, 39(Supp): 421-427

19 DeMaster D J, Mckee B A, Nittrouer C A, et al. Rates of sediment accumulation and particle reworking based on radiochemical 
measurements from continental shelf deposits in the East China Sea. Cont Shelf Res, 1985, 4: 143-158

20 Huh C A, Su C C. Sedimentation dynamics in the East China Sea elucidated from ${ }^{210} \mathrm{~Pb},{ }^{137} \mathrm{Cs}$, and ${ }^{239,240} \mathrm{Pu}$. Mar Geol, 1999, 160: 183 196

21 Fan D J, Yang Z S, Guo Z G. Review of the ${ }^{210} \mathrm{~Pb}$ dating in the continental shelf of China (in Chinese). Adv Earth Sci, 2000, 15: 297-302

22 Robbins J A, Edgington D N. Determination of recent sedimentation rates in Lake Michigan using $\mathrm{Pb}-210$ and Cs-137. Geochim Cosmochim Acta, 1975, 39: 285-304

23 Smith J N, Ellis K M. Transport mechanism for Pb-210, Cs-137 and $\mathrm{Pu}$ fallout radionuclides through fluvial marine systems. Geochim Cosmochim Acta, 1984, 46: 941-954

24 Xia X M, Xie Q C, Li Y, et al. ${ }^{137} \mathrm{Cs}$ and ${ }^{210} \mathrm{~Pb}$ profiles of the seabed cores along the East China Sea coast and their implications to sedimentary environment (in Chinese). Donghai Mar Sci, 1999, 17: 20-27

25 Wang G J. ${ }^{137} \mathrm{Cs}$ dating by annual distinguish for recent sedimentation: Samples from Erhai and Hongfeng Lake (in Chinese). Quat Sci,
1999, 1: 73-79

26 Wang G J. Progresses on ${ }^{137} \mathrm{Cs}$ and ${ }^{210} \mathrm{Pbe}_{\mathrm{x}}$ dating of lake sediments (in Chinese). Adv Earth Sci, 1995, 10: 188-192

27 Zhao Y Y. Many models of sediment geochemistry on China Sea continental shelf (in Chinese). Geol Sci, 1983, 307-314

28 Chen T B, Wu J J, Han J Y. An overview of present status of coal burning pollution and treatment technologies (in Chinese). Coal, 2006, 15: 1-4

29 Chen J P, Yu X D. Controlling techniques of sulphur oxide in coal combustion (in Chinese). J Liaoning Techn Univ, 2003, 22: 60-61

30 Zhao Y Y, Yan M C. Geochemistry of Shallow Sea Sediments of China (in Chinese). Beijing: Science Press, 1994

31 Hu S Y, Ran W H. Eclogical effects of arsenic in soil environment (in Chinese). Geophys Geochem Explor, 2006, 30: 83-86

32 Xiao G L, Sui F M, Wang H L. Economic History of the People's Republic of China (in Chinese). Beijing: Huawen Press, 2004. 6

33 Wang X, Yu Q H. The Economic History of Modern China (in Chinese). Dalian: Dongbei University of Finance Press, 2004. 11

Open Access This article is distributed under the terms of the Creative Commons Attribution License which permits any use, distribution, and reproduction in any medium, provided the original author(s) and source are credited. 